\title{
Volunteering in Israel - mobilized culture or norm
}

\begin{abstract}
The purpose of this paper is to present Israel volunteering norm and Israelis'attitude toward volunteering. Data shows that the rate of volunteering in Israel is declining and that Israelis attitude towards volunteering has changed. A committee on volunteering within the framework of the Interdisciplinary Round Table in the Prime Minister's Office was established to promote volunteering and social participation in Israel. There is a high-school program, to promote volunteering among teenagers that everyone must go through for 3 years. Much effort is dedicated to increasing motivation for volunteering, However, the volunteer percentage among adults are not rising. A Situational description.
\end{abstract}

Keywords: Israel, volunteers, norm, time of crisis

\section{Introduction}

$\mathrm{V}$ olunteering is a universal human phenomenon, and volunteers in the various societies engage for a variety of purposes and motives. In times of emergency, the Israeli public is revealed in its finery. The level of volunteerism increases, and everyone is there to help. Nonetheless, effective volunteering in an emergency begins in times of peace. The spirit of volunteering lies at the core of the Israeli/ Jewish notion. Since the beginning of Talmudic time, the scholars who supervised the "Community Chest" were volunteers. Moreover, the Tzedakah tradition (charity), which emerged from the injunction to "love your neighbor as yourself," encourages all people to help each other in times of difficulty and distress. Jewish schools (Cheder, Talmud Torah, and Yeshiva) in the diaspora were voluntary institutions, as well as the woman bathing facilities, brides’ aid groups, burial services 
and more. Most of the philanthropic activity was handled confidentially and often as "secret giving" (Matan Baseter). Thus, worldwide, the Jewish communities functioned under voluntary self-government. ${ }^{1}$

At the establishment of the State of Israel a group of young Zionists, most of them Jews, came as volunteers to help in establishing the new state by building farms, houses and industries. Israel welcomed European volunteers to the Kibutzim over the years, volunteers who assisted in constructing and renewing this form of settlement. Thus, Israel is well aware of the great value of volunteers. However, in Israel, data regarding volunteering indicate different trends. It is estimated that there are between 1 to 1.2 million volunteers in Israel (about 18\% of the Israeli population), and it's agreed that the rates of volunteering in Israel do not meet the potential of the Israeli people. ${ }^{2}$ But in times of crisis, emergency or need, a different trend of volunteering engagement is reflected. Unfortunately, the data of volunteers at a crisis is not uniform or formally collected for a measure. Nevertheless, there isn't much of a data about the benefits of the educational program for high school students that every one of them has to go through for 3 years. This article aims to provide an overview of volunteer patterns in Israeli culture and to address the question whether the lower rate of volunteer participation is the outcome of living under continues stress? And whether an educational program can increase the social responsibility among Israelis through volunteerism.

Van Til defined volunteerism through motivation and rewards. ${ }^{3}$ Volunteering may be identified as a helping action of an individual that has valued them, and yet is not aimed directly at a material gain or mandated or coerced by others. It is thereby different in definition from work, slavery, or conscription. Ellis and Noyes ${ }^{4}$ pointed out the importance of free will and saw volunteering as an affirmative social action, performing an act without coercion and going beyond one's basic obligations. Nevertheless, Smith expressed his disbelief in pure altruism by defining volunteering as a behavior that is "essentially motivated by the expectation of psychic benefits of some kind as a result of activities that have a market value greater than any remuneration received for such activities." ${ }^{5}$

The status of volunteering in Israel was emphasized by the establishment of Volunteer Organization in 1972. The Volunteer Organization is a public organiza-

${ }^{1}$ E. Herlitz, M. Weill, Hitnadvut be' Israel [Volunteerism in Israe], 2016, http://www.ivolunteer.org.il (Hebrew) [10.11.2018].

2 JDC Israel, Meyzam hahitnadvut [The volunteer project]. http://www2.jdc.org.il/he/324, 2014 (Hebrew) [14.11.2018].

${ }^{3}$ Til, J. van, Mapping the Third Sector: Voluntarism in a Changing Social Economy, The Foundation Center, New York 1988.

${ }^{4}$ S.J. Ellis, K.H. Noyes, By the People: A History Of Americans As Volunteers. Jossey-Bass Inc Pub. San Francisco 1990.

${ }^{5}$ Altruism, Volunteers, and Volunteerism, "Journal of Voluntary Action Research" 1981, Vol. 10(1), pp. 21-36. 
tion, registered as non-profit, and financed by government funds. The organization consists of public figures and public representatives, government agencies, research institutions and voluntary organizations. Its main purpose is to create an interest, to promote and accelerate volunteerism and to increase public awareness of Volunteering as a value. ${ }^{6}$

\section{World statistics}

Volunteering has a significant and profound contribution to the strengthening of civil society and to social cohesion and solidarity, out of a sense of belonging to the community and the expression of the citizens who bear responsibility for the society in which they live in. Studies about the population percentage involved in volunteer work, show stable trends in different countries. ${ }^{7}$ For example, about half of American adults' volunteers, while in Europe, only one-third volunteers. This disparity indicates that it is possible that social norms and other characteristics of the society and community influence the altruistic tendency and volunteering habits. Norm is the social expectations that guide behavior. Norms explain why people do what they do in given situations. It's a principle of right action binding upon the members of a group and serving to guide, control, or regulate proper and acceptable behavior. ${ }^{8}$

In other studies of altruism and volunteering in different societies, the structural and cultural perspectives are considered. Some ${ }^{9}$ have studied structural features such as community size and networking, ${ }^{10}$ while others focused on cultural aspects, such as religion, social values, social pressure and reciprocity. ${ }^{11}$

In Israel, volunteer data are not uniform, yet questionnaires conducted among adults indicate diverse trends. It is estimated that there are between 0.5 million to 1.5 million volunteers in Israel (about 18\%) and it's agreed that the rates of volunteering in Israel do not meet the potential of the Israeli people. The Israeli

${ }_{6}$ JDC Israel, Meyzam hahitnadvut [The volunteer project], http://www2.jdc.org.il/he/324, 2014 (Hebrew) [14.11.2018].

7 M. O’Neil, Research on Giving And Volunteering: Methodological Considerations, "Nonprofit And Voluntary Sector Quarterly" 2001, Vol. 30(3), p. 505.

8 Webster M. Dictionary, Norm, from https://www.merriam-webster.com/dictiona [10.11.2018].

${ }_{9}^{9}$ L.A, Penner, Volunteerism and social problems: Making things better or worse? "Journal of Social Issues” 2004, Vol. 60(3), pp. 645-666.

10 D.H. Smith, Determinants of Voluntary Association Participation and Volunteering: A Literature Review, “Nonprofit and Voluntary Sector Quarterly” 1994, Vol. 23(3), pp. 243-263. https://doi.org/10.1177/089976409402300305 [8.11.2018].

${ }^{11}$ R.H Bekkers, Giving and volunteering in the Netherlands: Sociological and psychological perspectives, University of Utrecht 2004. 
Table 1. Volunteering in Israel

\begin{tabular}{|c|c|c|}
\hline \multicolumn{3}{|c|}{ Volunteer survey 2013 - Israel (\%) } \\
\hline 19.9 & Total & Total from Population \\
\hline 18.3 & Woman & Gender \\
\hline 21.6 & Man & \\
\hline 24.5 & 4,001 & Avg income per capita \\
\hline 17.8 & $2001-4000$ & \\
\hline 16.3 & up to 2000 & \\
\hline 16.0 & not in labor force & Employment Status \\
\hline 14.9 & Unemployed & \\
\hline 22.0 & Employed & \\
\hline 38.2 & ultra-Orthodox Jews & Degree of religiosity - Jews only \\
\hline 32.8 & Religious & \\
\hline 18.3 & Traditional & \\
\hline 20.8 & Secular (not religious) & \\
\hline 7.7 & Arab & National group \\
\hline 22.8 & Jews & \\
\hline 27.4 & Academic certificate & Education \\
\hline 22.1 & Post-secondary certificate & \\
\hline 18.6 & Matriculation certificate & \\
\hline 14.8 & High school diploma & \\
\hline 12.5 & $\begin{array}{l}\text { No certificate or completion of elemen- } \\
\text { tary school / junior high school }\end{array}$ & \\
\hline 16.4 & $65^{+}$ & Age group \\
\hline 19.7 & $45-64$ & \\
\hline 21.0 & $20-44$ & \\
\hline
\end{tabular}

Source: Central Bureau of Statistics Israel 2013 (Hebrew). 
volunteer activity is lower than the average of most Western countries. The rate of volunteering is, e.g. ${ }^{12}$ in:

- Canada - 44\%

- the Netherlands - 45\%,

- the United Kingdom - 46\%,

- Sweden - 48\%,

- Israel - 18\%-20\%.

In Israel, there are 14,000 active volunteer organizations. ${ }^{13}$

The Israelis chose to volunteer in four main types of organizations: 1) Welfare and assistance services for the needy, 2) Security and rescue organizations, 3) Educational organizations and 4) Health organizations. The Central Bureau of Statistics issued report in 2013, which tracks valuable national and regional statistics on volunteering among Israelis aged 20 years and above.

The following conclusions may be drawn from Table 1:

- One in five, 20\% (about one million people) engaged in volunteer activity in the past year: $22 \%$ of men and $18 \%$ of women, $23 \%$ of Jews and $8 \%$ of Arabs.

- $48 \%$ of the volunteers volunteered through a formal organization, $38 \%$ volunteered privately, and 14\% volunteered both within an organization and privately.

- $37 \%$ of the volunteers volunteered to assist the needy, $27 \%$ volunteered in the field of education and culture, $10 \%$ in the public order sector, $10 \%$ in the field of health (MDA - Israel Red Cross, hospitals, etc.) 6\% in religious activities, 3\% defended and protected nature and animals, and 7\% volunteered in other fields.

- Among young people, there are higher rates of volunteerism (21\% aged $20-44$ and 20\% aged 45-64), compared with those aged 65 and over (16\%).

- The higher the level of education, the higher the rates of volunteerism.

- Among the Jewish population, a particularly high percentage of volunteers was found among the ultra-Orthodox (38\%) and the religious (33\%).

\section{Volunteering in times of emergency, crisis or need}

Emergency and crisis are defined differently in different places of the world, taking into consideration own national experience. Nonetheless, there is a common denominator for emergencies. In Israel, the "Home Front Command” defines state of emergency or crisis as a situation liable to harm the individual, the family, the organization, and the community, remove them from physical and mental equilibrium and cause disruptions and difficulties in functioning. The source of a state of

12 Charity aid foundation. A Global View of Giving Trends, 2014, https://www.cafonline. org/docs/default-source/about-us-publications/caf_wgi2014_[10.11.2018].

13 Midot, http://www.midot.org.il/english-2015 [20.11.2018]. 
emergency is an external factor, which takes place with great force, without the system being able to prevent its appearance. ${ }^{14}$

Every year, the High Holidays reveal the "beautiful Israeli" in all its splendor. At this time, many commercials appear calling the public to donate food for the holiday meals or host a stranger for the holiday dinner. People donate goods while shopping for the holiday, distributing the food in the centers and shelters or even hosting unknown needy people for a holiday. The same happens in time of armed conflict, crisis, or emergency. At a time of conflict, people tend to invite families from the conflict area to stay with them; people donate warm clothing, food and snacks to soldiers at rest areas, students and youth movements spend time with the young kids in safety shelters: playing, teaching, etc. During the last tenyears, Israel went through 4 situations of crisis and conflicts; Itis estimated that 6.000 volunteers were involved in different regions. This way of spontaneous volunteering is hard to quantify and was not measured; Azulay mentioned that data estimates rely on the mayors' reports, press reports, and social media. ${ }^{15}$

In disasters and emergencies, the public is the object of rescue and treatment, but at the same time, the public can be the rescue forces. ${ }^{16}$ Volunteering is a valuable part of every healthy community. The volunteers come from all segments of society and often provide essential services. Everyone has the potential to contribute strength and resources in times of emergency, and many continue to assist after the event, rehabilitating the affected communities. The volunteer organizations distinguish between "organized” volunteers and “spontaneous” volunteers. The spontaneous volunteers have proven to be a cost-effective resource in short-term recovery, force multiplier, and they offer a wide range of expertise and experience though not always needed. Israel as a nation is one of the first to volunteer spontaneously helping other countries in crisis. From earthquakes, Tsunami, searches and rescue, to humanitarian aid, doctors and field hospitals. This is a non-measurable force that cannot be ignored, and the question why the Israeli people do not volunteer more often has occupied the decision-makers in Israel.

\section{What was done? What else can be done?}

The aim to expand the number of volunteers $\square$ and the quality of their volunteering led in 2015 to the establishment of a committee on volunteering within the frame-

${ }^{14}$ Home Front Command: http://www.oref.org.il/894-en/Pakar.aspx [14.11.2018].

15 Y. Azulay, M.O. Yezuka, P. Metachnen, L. Y. Mitnadvim, Lessons Learned from Operation Cast Lead: Home Front Command Plans to Set up Volunteer Units, Haaretz News Paper 2009 (Hebrew).

16 Y. Soffer. Model Leumi rav-irguni lehazalat chaim beeirua reidat adama, beshlave hamuchanut ve ha mane hamiyadi [A national multi-organizational model for saving lives in an earthquake. Ben Gurion University, Beer-Sheva 2006 [Hebrew]. 
work of the Round Table in the Prime Minister's Office in order to promote volunteering and social participation in Israel (named; The Israeli volunteer project). The National Council for Volunteering in Israel is a registered nonprofit organization. It was founded in 1972 as an external body of the Government of Israel, with the aim of reducing social gaps by encouraging volunteers to participate. The Council is the oldest volunteer organization in Israel, providing services to volunteers and volunteer organizations. The Council goals and objectives are:

- Representation of the volunteer movement in Israeli society;

- Promoting volunteer work on the national level and at the community level;

- Active as political lobby issues that are within the area of the council;

- Increasing awareness for personal involvement in social and community activities.

The education ministry has initiated a high-school program encouraging teenagers to volunteer. Every high school student undergoes a mandatory school program that requires him/her to volunteer for $6 \square 0$ hours yearly for three years. The volunteer experience will be in a field where continuous activity is possible throughout the year. The educational staff at the school and in the place of volunteering will train the student and will implement support and guidance to enable the student to cope with his task. Volunteering may take place in various areas: Agriculture, help and rescue organizations, environmental organizations, and assistance to students in school. The students are assessed by the school educator on a yearly basis, based on the information received from the voluntary teams accompanying the student (Confirmation of attendance and quality of work). This program was not researched for its impact on social involvement nor prosocial behavior.

\section{Barriers to volunteering - Israeli context}

The question of Israelis not volunteering on a regular basis might be answered in Schmid study. Schmid pointed to personal obstacles that characterize the Israeli public at the beginning of the 21st century:

1. Lack of education for giving.

2. A sense of personal disappointment from the lack of responsibility and commitment of the state towards its citizens. This feeling emerges as a response to the privatization of public and welfare services. As a result, the citizens' commitment to the state and its institutions has been undermined.

3. Liability burden - a feeling that the Israeli citizen has many duties toward the state in comparison to other western countries.

4. Israel sense of collectiveness has evaporated and changed to a high level of individualism, egocentrism, materialism, and consumerism. The Israeli citizen is focused on promoting personal goals and is less interested in social and national 
goals and needs. Considering all this, there is less motivation to contribute and volunteer for the benefit of the public, except in emergency situations where there are increasing manifestations of giving. ${ }^{17}$

Barriers that characterize non-volunteer youth are consistent with those identified among the none-volunteer adult population. However, among the youngsters, the lack of awareness of the possibility to volunteer and lack of guidance in referring to volunteering, are evident as reasons for not volunteering. Bar pointed out additional barriers to youth volunteering: The public atmosphere in Israel does not emphasize or promotes volunteering in general and youth volunteering in particular; lack of professional understanding of how to encourage and develop youth volunteering; lack of role models; \& no cooperation between the different sectors that concern the lives of adolescents in Israel. ${ }^{18}$ These reasons are consistent with child behavior patterns of action following the guidance or direction of an authoritative figure.

\section{Conclusion}

Much effort is made by the government, through official volunteer organization, to maintain volunteerism, increase awareness and increase the number of participants. There are changes in approaches towards volunteering in Israeli society as people become more self-centered, less interested in the social order, and some believe that donating money, philanthropy, is equivalent to volunteering. But at time of crisis and need people will more likely volunteer, help in any way or donate money. Among Israelis, volunteering is an act of mobilization rather than a common norm in behavior. It servers the Jewish/Israeli Ethos: all for one, and one for all, of mutual responsibility (Kol Israel Arevim Ze La Ze). The ethos is a major motivator and catalyst in the creation of social cohesion, unity and a cooperative spirit to promote morality and ideas. The ethos can be changed over time because of the acceptance and internalization of new ideas through a natural and ongoing educational process. There for it is essential to continue trying to educate and to create an effective educational system of social involvement as a lasting social norm. Education to volunteering should start at kindergarten age all the way through high-school. This way will enable to ingrain what mutual responsibility is.

${ }^{17}$ M. Schmid, Me 'afyeney haphilantropya be'Israel bamea'21: me ni im, chasamin, dilemot ve etgarim [Characteristics of philanthropy in Israel in the 21st century: motives and barriers to giving, dilemmas, challenges and directions for future action], Hebrew University Israel, Jerusalem: 2011 (Hebrew).

${ }^{18}$ R. Bar, Pitua'ch ve'kidum hitnadvut noa'r ve tzeirim beisrael [Developing and promoting volunteerism for young people in Israel], 60 years of education in Israel: Past, Present Future. The Mandel Institute 2008, pp. 118-113 (Hebrew). 


\section{Literature}

Azulay Y., Yezuka M.O., Metachnen P., Mitnadvim L.Y., Lessons Learned from Operation Cast Lead: Home Front Command Plans to Set up Volunteer Units, Haaretz News Paper 2009 (Hebrew).

Bar R., Pitua'ch ve'kidum hitnadvut noa'r ve tzeirim beisrael, [Developing and promoting volunteerism for young people in Israel] 60 years of education in Israel: Past, Present Future, The Mandel Institute 2008 (Hebrew).

Bekkers R.H., Giving and volunteering in the Netherlands: Sociological and psychological perspectives, University of Utrecht 2004.

Central Bureau of Statistics, Volunteering in Israel, Selected Data from the 2013.

Charity aid foundation. A Global View of Giving Trends, 2014, https://www.cafonline.org/ docs/default-source/about-us-publications/caf_wgi2014_

Ellis S.J., Noyes K.H., By the People: A History Of Americans As Volunteers. Jossey-Bass Inc Pub; San Francisco 1990.

Herlitz E., Weill M., Hitnadvut be' Israel [Volunteerism in Israe], http://www.ivolunteer. org.il 2016 (Hebrew).

Home Front Command: http://www.oref.org.il/894-en/Pakar.aspx

JDC Israel, Meyzam hahitnadvut [The volunteer project]. http://www2.jdc.org.il/he/324; 2014 (Hebrew).

Midot, http://www.midot.org.il/english-2015

O’Neil M., Research on Giving And Volunteering: Methodological Considerations, "Nonprofit And Voluntary Sector Quarterly" 2001, Vol. 30(3).

Penner L. A,, Volunteerism and social problems: Making things better or worse? "Journal of Social Issues” 2004, Vol. 60(3).

Schmid M., Me 'afyeney haphilantropya be'Israel bamea'21: me ni im, chasamin, dilemot ve etgarim [Characteristics of philanthropy in Israel in the 21st century: motives and barriers to giving, dilemmas, challenges and directions for future action], Hebrew University Israel, Jerusalem: 2011 (Hebrew).

Smith D.H., Determinants of Voluntary Association Participation and Volunteering: A Literature Review, “Nonprofit and Voluntary Sector Quarterly” 1994, Vol. 23(3), https:// doi.org/10.1177/089976409402300305

Smith, Altruism, Volunteers, and Volunteerism, "Journal of Voluntary Action Research" 1981, Vol. 10(1).

Soffer Y., Model Leumi rav-irguni lehazalat chaim beeirua reidat adama, beshlave hamuchanut ve ha mane hamiyadi [A national multi-organizational model for saving lives in an earthquake. Ben Gurion University, Beer-Sheva 2006 (Hebrew).

Til J. van, Mapping the Third Sector: Voluntarism in a Changing Social Economy, The Foundation Center, New York 1988.

Webster M. Dictionary, Norm, from https://www.merriam-webster.com/dictiona 
